\title{
The acid-catalyzed interaction of melanin with nitrite ions. An EPR investigation
}

\author{
Zenon Matuszak, \\ Collin F. Chignell ${ }^{\dagger}$, \\ Krzysztof J. Reszka ${ }^{\dagger}$
}

\begin{abstract}
The interaction of synthetic dihydroxyphenylalanine (DOPA) melanin (DM) with nitrite ions, $\mathrm{NO}_{2}^{-}$, in the $\mathrm{pH}$ 3.6-7.0 range, has been investigated using electron paramagnetic resonance (EPR). We found that especially at $\mathrm{pH}<5.5$ (from ca. 5.5 to 3.6) the reaction of DM with nitrite generated large quantities of new melanin radicals, which implies the involvement of nitrous acid, $\mathrm{HNO}_{2}$, in the radical formation process. Measurements carried out at constant $\mathrm{pH}$ of 3.6 showed that the melanin signal increased together with nitrite concentration, reaching a plateau level which was more than fourfold larger compared to the initial signal amplitude observed in a nitrite-free buffer of the same $\mathrm{pH}$. The effects of nitrite and DM concentrations on the melanin-free radical content were also investigated. It is proposed that the radicals are generated by one electron oxidation of melanin ortho-hydroquinone groups to ortho-semiquinones by $\mathrm{HNO}_{2}$ or related nitrogen oxides such as $\mathrm{NO}_{2}{ }^{\cdot}$ radicals. The possible involvement of nitric oxide $\left({ }^{\circ} \mathrm{NO}\right)$ and peroxynitrite $\left(\mathrm{ONOO}^{-}\right)$in $\mathrm{DM}$ oxidation was also examined. In air-free solutions, nitric oxide per se did not generate melanin radicals; however, in the presence of oxygen a marked increase in the melanin EPR signal intensity was observed. This result is interpreted in terms of the generation of radicals via the oxidation of DM by peroxynitrite. Our findings suggest that melanin can function as a natural scavenger of nitrous acid and some nitrous acid-derived species. This property may be relevant to physiological functions of melanin pigments in vivo.
\end{abstract}

Key words: EPR $\bullet$ melanin $\bullet$ nitrite $\bullet$ nitrogen dioxide $\bullet$ nitrous acid $\bullet$ radicals

\section{Z. Matuszak}

Department of Medical Physics and Biophysics, Faculty of Physics and Applied Computer Science, AGH-University of Science and Technology, 30 Mickiewicza Ave., 30-059 Krakow, Poland, Tel.: +48 12617 4454, Fax: +48 12634 0010, E-mail: Zenon.Matuszak@fis.agh.edu.pl

C. F. Chignell, K. J. Reszka

Laboratory of Pharmacology and Chemistry, National Institute of Environmental Health Sciences (NIH),

P. O. Box 12233, Research Triangle Park, North Carolina 27709, U.S.A.

Received: 1 October 2014

Accepted: 30 January 2015

\section{Introduction}

Melanins are natural pigments responsible for the coloration of skin and hair in animals and humans. The biosynthesis of melanins is confined to highly specialized cells, melanocytes, which contain tyrosinase, a unique enzyme capable of hydroxylating the amino acid tyrosine to dihydroxyphenylalanine (DOPA) and oxidizing DOPA to DOPA-quinone [1]. The latter is rapidly converted to 5,6-dihydroxyindole (5,6DHI) and 5,6-dihydroxyindole-2-carboxylic acid 5,6DHI(2CA), which upon oxidation and condensation yields eumelanin, the brown-to-black pigment (Fig. 1) [1, 2]. An alternative route to the pigment, not involving tyrosinase, is via the oxidation of DOPA, or 5,6DHI(2CA), by peroxidase $/ \mathrm{H}_{2} \mathrm{O}_{2}$ systems (Fig. 1) [3].

EPR investigations have shown that melanin contains free radicals, mostly, ortho-semiquinone $\left(\mathrm{Q}^{-}\right)$in nature [2]. It is believed that these radicals 


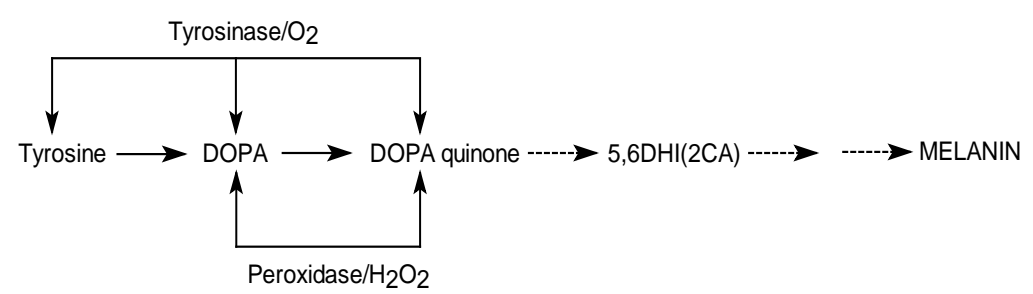

Fig. 1. Schema of melanin synthesis.

are derived primarily from two structural subunits of eumelanin, 5,6DHI and 5,6DHI(2CA), which are readily oxidized to semiquinone and quinone forms. The content of the radicals in melanin can be changed by changing $\mathrm{pH}$ of the medium, by reacting melanin with oxidizing and reducing species, and by interaction with metal ions [2, 4-7]. Using EPR it has been shown that melanin scavenges free radicals [8] and deactivates other reactive species, such as excited states of photosensitizers and singlet oxygen [9].

It is believed that the most important biological role of melanin is the protection of the skin against ultraviolet (UV) light-induced damage. In this respect an important role is played by the ability of melanin to absorb and scatter the light, and the capacity to react with free radicals and to deactivate other reactive species produced in the course of photochemical/photosensitized reactions. Specifically, the ability of eumelanin to scavenge free radicals has been linked to the high resistance to chemo- and radiotherapy of melanoma, a form of pigmented skin cancer.

Some findings suggest that the development and growth of tumors including melanoma may be regulated by nitric oxide ('NO) and NO-derived species. It has been reported that both melanoma and normal melanocytes contain constitutive nitric oxide synthase (NOS), an enzyme responsible for the formation of $\mathrm{NO}$ from arginine, and that the activity of NOS in melanoma is significantly greater than in normal melanocytes [10]. In addition, it has been found that in contrast to nonmetastatic melanoma cells, highly metastatic melanoma cells express a high level of inducible nitric oxide synthase and nitric oxide production [11-13]. ${ }^{\circ} \mathrm{NO}$ regulates many physiological processes, including anticancer and antibacterial action of macrophages [14]. It is involved, presumably, in the control of the growth and metastasis of tumors through the regulation of angiogenesis and platelet aggregation [10, 15-17]. -NO is also the natural precursor of other reactive nitrogen species (RNS) such as the nitrogen dioxide radical $\left(\mathrm{NO}_{2}{ }^{\circ}\right)$ and in vivo produced nitrite and nitrate [18]. It is therefore important to know whether melanin may react with radical and nonradical species produced along the nitric oxide pathway and whether by doing so, it can affect the course of the disease. Before now it has not been known whether melanin can react with any of these reactive species.

In the present work we have investigated the interaction between synthetic DOPA-melanin (DM) and nitrite anions, $\mathrm{NO}_{2}^{-}$, as a function of $\mathrm{pH}$. We found that the reaction of DM with nitrite generates melanin radicals but only in acidic solutions, which suggests the involvement of nitrous acid,
$\mathrm{HNO}_{2}$, in the radical formation process. The rationale behind this study is that: (i) the intracellular $\mathrm{pH}$ in cancer cells is acidic [17] and, in particular, the intramelanosomal $\mathrm{pH}$ can be as low as 3-4 [19, 20]; (ii) the $\mathrm{NO}_{2}^{-}$ions present in vivo undergo protonation in the acidic environment of cancer cells to form $\mathrm{HNO}_{2}, \mathrm{pK}_{\mathrm{a}}\left(\mathrm{HNO}_{2} / \mathrm{NO}_{2}^{-}\right)=3.35$ [21]; (iii) the melanin pigment and products of NOS activity, including $\mathrm{HNO}_{2}$, may be present simultaneously in melanoma where they may react with each other in situ. Because DM is considered to be an adequate model of the natural eumelanin pigment present in the skin this study suggests that endogenous melanin may scavenge nitrous acid in vivo. $\mathrm{HNO}_{2}$ is a powerful toxin and mutagen and its scavenging by melanin may be pertinent to the cytoprotective action of the pigment. Possible participation of related oxygen oxides has also been considered based on the dependence of radical formation on the presence of oxygen, superoxide dismutase, and catalase (CAT).

\section{Materials and methods}

DOPA-melanin was obtained from Dr. C. C. Felix (Medical College of Wisconsin, Milwaukee, WI, U.S.A.) and the method of its preparation was described in [7]. Sodium nitrite, CAT, superoxide dismutase (SOD), and DEA/NO (sodium 2- $(N$, $\mathrm{N}$-diethylamino)-diazenolate-2-oxide) were purchased from Sigma-Aldrich Chemical Company (Milwaukee, WI, U.S.A.). The stock solution of DEA/NO (10 mM) was prepared in $20 \mathrm{mM} \mathrm{NaOH}$ and the release of NO by DEA/NO was controlled by NO-electrode (ISO-NOP200 electrode, World Precision Instruments, Sarasota, FL, U.S.A.).

Peroxynitrite was synthesized according the method described in [22], its concentration was controlled spectrophotometrically $\left(\varepsilon_{302}=\right.$ $1670 \mathrm{M}^{-1} \cdot \mathrm{cm}^{-1}$ ) [23]. The reaction was initiated by the addition of a small aliquot $(100 \mu \mathrm{L})$ of the nitrite solution (5 mM) to DM dissolved in a buffer of appropriate $\mathrm{pH}$. Buffers used in this work were: sodium acetate/acetic acid $(0.1 \mathrm{M})$ for $\mathrm{pH} 3.6,4.0,4.7$, 5.3 , and 5.8 , and phosphate buffers $(0.1 \mathrm{M})$ for $\mathrm{pH}$ 6.5 and 7.0. EPR measurements were performed using a Varian E-Line Century Series EPR spectrometer operating at $9.4 \mathrm{GHz}$ with a $100 \mathrm{kHz}$ modulation frequency and equipped with a $\mathrm{TM}_{110}$ cavity. Measurements were performed in a flat quartz aqueous cell at room temperature. The deoxygenated samples were prepared by purging with nitrogen in the EPR cell for 5 min prior to the addition of an oxygen-free solution of $\mathrm{NaNO}_{2}$, after which bubbling was continued for another $30 \mathrm{~s}$. 


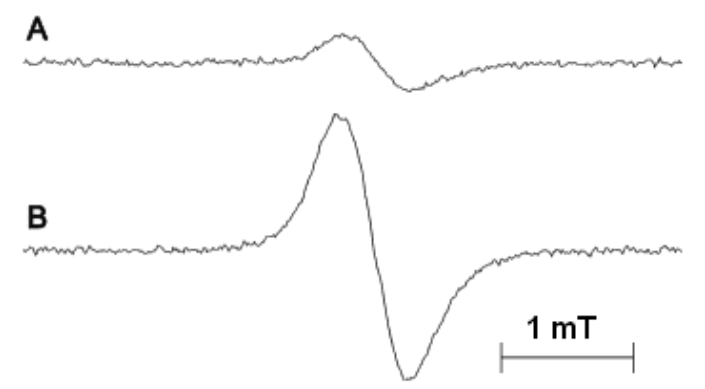

Fig. 2. EPR spectra of DM at $\mathrm{pH} 3.6$ in the absence (A) and the presence of $0.5 \mathrm{mM}$ nitrite $(\mathrm{B})$.

Typical instrumental settings for the recording the melanin EPR signals were: microwave power $10 \mathrm{~mW}$, modulation amplitude $0.165 \mathrm{mT}$, time constant $0.25 \mathrm{~s}$, scan rate $4 \mathrm{~min} / 10 \mathrm{mT}$, and the appropriate receiver gain level. At $10 \mathrm{~mW}$ the melanin EPR signals were partially saturated, especially in air-free solutions, but this power level was chosen because it allowed the prompt detection of relatively low concentrations of the pigment. We have found that for the purpose of this work this partial saturation can be ignored because experiments carried out on selected samples using the nonsaturating power of 0.5 and $1 \mathrm{~mW}$ have led to identical conclusions as those carried out at $10 \mathrm{~mW}$. Because neither line shape nor line width of melanin EPR signal changed in the course of the reaction, concentrations (relative) of melanin radicals were determined by measuring amplitudes of the respective EPR signals. This approach and a double integration method yielded similar results. Simulation of the spectra was performed using the software described in [24].

\section{Results}

The EPR spectrum of DM in pH 3.6 buffer is a symmetrical single line with a peak-to-peak line width $\left(\Delta B_{\mathrm{pp}}\right)$ of approximately $0.5 \mathrm{mT}$ (Fig. $\left.2 \mathrm{~A}\right)$. After the addition of $\mathrm{NaNO}_{2}$ (final concentration, $0.5 \mathrm{mM}$ ), the amplitude of the signal increased by a factor of about 4.4, indicating the formation of a large number of new free radical centers in DM.

This change in the signal intensity occurred rapidly (in less than $1 \mathrm{~min}$ ) so the time course of this initial increase could not be recorded in static (offline) EPR experiments. Under applied conditions this significant increase in the radical content in DM did not cause any noticeable changes in the line shape or $\Delta B_{\mathrm{pp}}$ of the melanin EPR signal. Accordingly, signals recorded prior to and after the addition of nitrite could be simulated assuming the existence of only one type of radical center in DM $(r=0.98-0.99)$.

\section{Dependence on $\mathrm{pH}$}

The generation of melanin radicals by nitrite is strongly $\mathrm{pH}$ dependent. When the $\mathrm{pH}$ of the sample containing DM and nitrite was decreased from 7.0 to 3.6, the amplitude of the melanin EPR signal in-

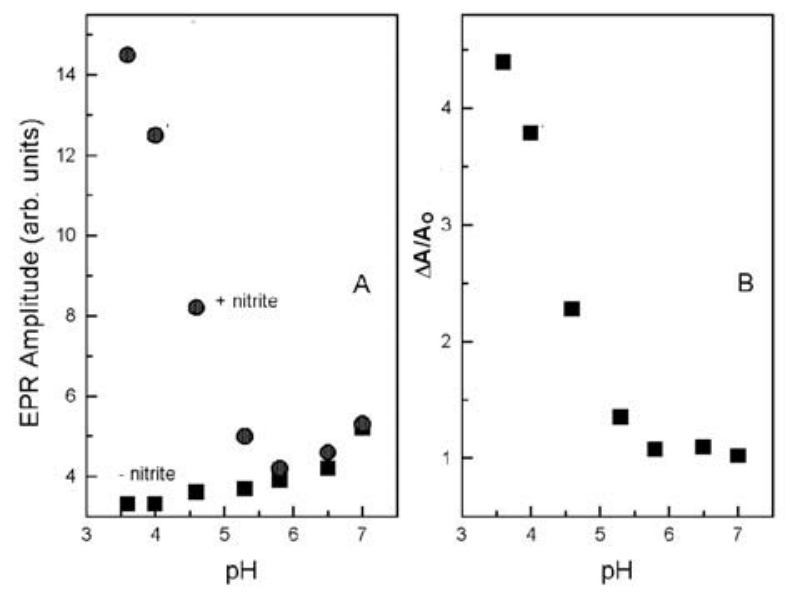

Fig. 3. Dependence of the melanin ( $\mathrm{DM} \sim 0.55 \mathrm{mg} / \mathrm{mL}$ ) EPR signal amplitude on $\mathrm{pH}$. (A) Sample containing DM and nitrite $\left(\mathrm{NaNO}_{2}=0.5 \mathrm{mM}\right)$, line $\bullet$; nitrite omitted, line $\mathbf{a}$. (B) The net dependence of the melanin signal on $\mathrm{pH}$ after correction for the effect of $\mathrm{H}^{+}$alone. The amplitudes are expressed relative to the amplitude measured at a given $\mathrm{pH}$ in the absence of $\mathrm{NaNO}_{2}, \Delta A / A_{O}$, where $\Delta A=A_{N}-A_{O} ; \mathrm{A}_{N}$ and $\mathrm{A}_{O}$ correspond to EPR amplitudes measured in the presence and absence of nitrite, respectively.

creased about threefold (Fig. 3A, line $\bullet$ ). Note that in the control (nitrite omitted), the decrease in $\mathrm{pH}$ alone induced a moderate, about $38 \%$, decrease in signal amplitude (Fig. 3A, line $\mathbf{\square}$ ). It is known that changes in $\mathrm{pH}$ affect the intensity of the melanin signal. A significant increase in radical concentration has been observed only in alkaline solutions, while at acidic $\mathrm{pH}$ the radical content is only slightly smaller than that at neutral $\mathrm{pH}$. Thus the action of $\mathrm{H}^{+}$alone is the opposite of the action of $\mathrm{HNO}_{2}$. Figure $3 \mathrm{~B}$ shows the net dependence of the melanin signal on $\mathrm{pH}$ after the correction for the effect of $\mathrm{H}^{+}$alone. In the presence of nitrite the relationship between the EPR signal amplitude of $\mathrm{DM}$ and the $\mathrm{pH}$ is linear in the $\mathrm{pH}$ range 3.6-5.5 $(r=-0.99)$.

The constant level of the signal amplitude was attained approximately 2 min from the start of the reaction and the signals did not change over the period of several minutes.

\section{Dependence on $\mathrm{NaNO}_{2}$}

The dependence on $\mathrm{NaNO}_{2}$ was studied at $\mathrm{pH}=3.6$ because at this $\mathrm{pH}$ the generation of radicals was most efficient. When the concentration of $\mathrm{NaNO}_{2}$ increased the melanin signal also gradually increased reaching plateau at a fourfold higher level compared to control (Fig. 4).

\section{Dependence on melanin concentration}

The amplitude of EPR signal increased linearly with DM concentration (Fig. 5, line $\bullet$ ). In the presence of $\mathrm{NaNO}_{2}$ the increase was considerably larger and it was still proportional to DM concentration (Fig. 5, line $\mathbf{\square}$ ). 


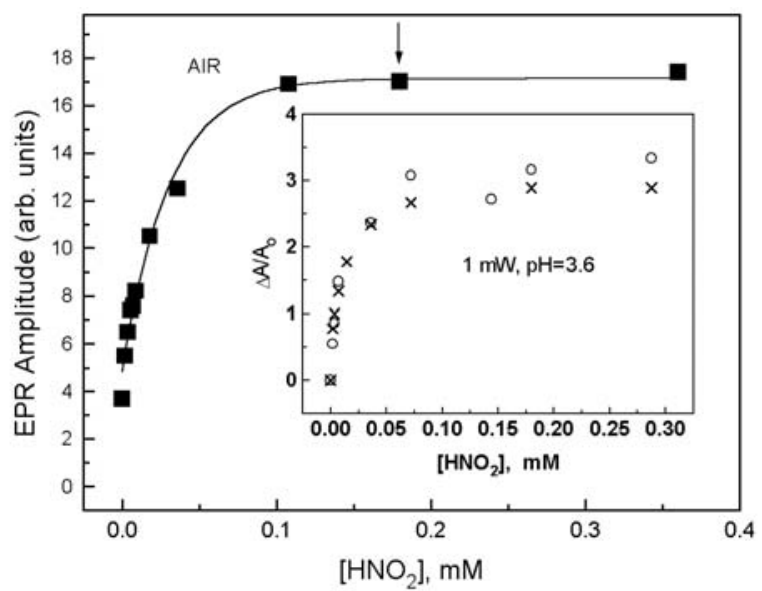

Fig. 4. Dependence of the melanin EPR signal amplitude on $\mathrm{HNO}_{2}$ in air-saturated buffers ( $\left.\mathrm{pH} 3.6\right)$, line $\mathbf{~ . ~ T h e ~}$ signals were measured using $10 \mathrm{~mW}$ power. The arrow indicates a data point used as a reference in the investigation of the effect of melanin concentration on the nitrite-induced radical generation (Fig. 5). Inset shows the EPR amplitude plotted vs. $\mathrm{HNO}_{2}$ measured using $1 \mathrm{~mW}$ microwave power for melanin samples in air-saturated $(\mathrm{o})$ and air-free $(\times) \mathrm{pH} 3.6$ buffers. The experimental data points represent the relative increase of the signal amplitude, $\triangle A / A_{O}$, where $\Delta A=A_{N}-A_{O} ; A_{N}$ and $A_{O}$ correspond to EPR amplitudes measured in the presence and absence of nitrite, respectively. Concentrations of nitrous acid $\mathrm{HNO}_{2}$ refer to $\mathrm{NO}_{2}$ calculated using the expression $\mathrm{HNO}_{2}=[\mathrm{T}] /\left(1+10^{\mathrm{pH}-\mathrm{pKa}}\right)$ where $[\mathrm{T}]$ is the total concentration of nitrite $(0.5 \mathrm{mM}) \cdot \mathrm{pK}_{\mathrm{a}}\left(\mathrm{HNO}_{2} / \mathrm{NO}_{2}^{-}\right)=3.35$ [21].

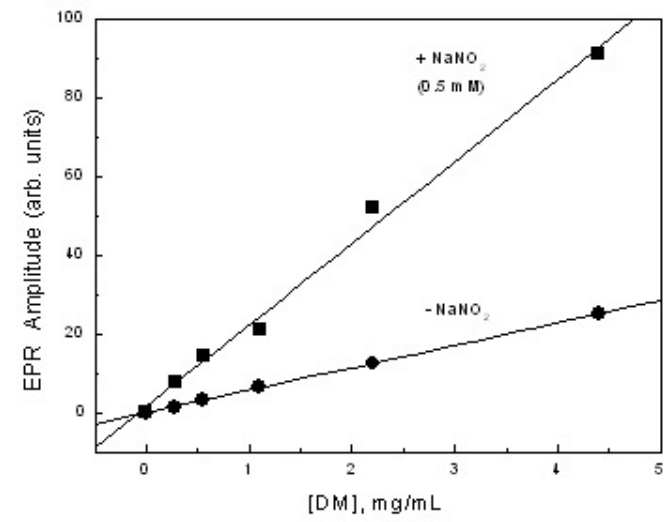

Fig. 5. Dependence of the melanin EPR signal amplitude on melanin concentration in the absence $(\bullet)$ and presence (匹) of $\mathrm{NaNO}_{2}\left(\mathrm{NaNO}_{2}=0.5 \mathrm{mM}, \mathrm{HNO}_{2}=0.18 \mathrm{mM}\right)$ in aerated $\mathrm{pH} 3.6$ buffer. The concentration of nitrite used was sufficient to reach the plateau level of the EPR signal for a DM concentration of $0.5 \mathrm{mg} / \mathrm{mL}$ (point marked with an arrow in the plateau region in Fig. 4).

\section{Reaction of DM with nitric oxide and peroxynitrite} and the effects of SOD and CAT

It is possible that some RNS other than $\mathrm{HNO}_{2}$ also participate in the growth of EPR melanin signal after adding nitrite. In order to check this possibility, taking into account some aspects of melanin chemistry, the additional experiments were performed. Results are presented in Fig. 6.

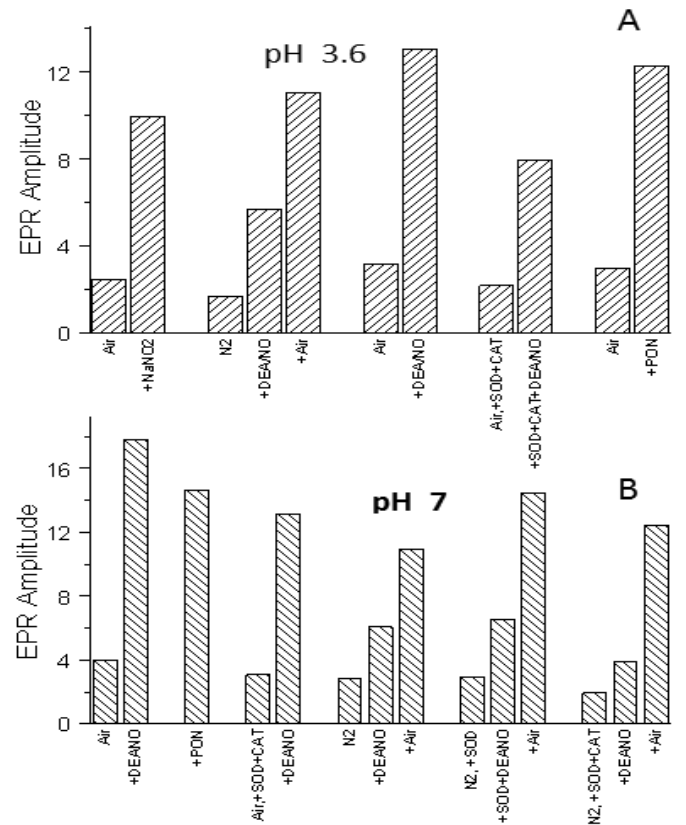

Fig. 6. (A) Effect of $\mathrm{NaNO}_{2}(0.5 \mathrm{mM})$, DEA/NO (1 mM) and peroxynitrite (PON) $(2 \mathrm{mM})$ on melanin $(0.55 \mathrm{mg} /$ $\mathrm{mL})$ EPR signal amplitude in aerated and deaerated $\mathrm{pH}=3.6$ buffer. (B) Effect of DEA/NO $(1 \mathrm{mM})$ and PON $(2 \mathrm{mM})$ on melanin $(0.55 \mathrm{mg} / \mathrm{mL})$ EPR signal amplitude in aerated and deaerated $\mathrm{pH}=7.0$ buffer. In some experiments CAT $(0.2 \mathrm{mg} / \mathrm{mL})$ and SOD $(0.1 \mathrm{mg} / \mathrm{ml})$ were present.

\section{Effect of $\mathrm{H}_{2} \mathrm{O}_{2}$}

It is known that in aerated solutions melanin undergoes autooxidation, producing superoxide and hydrogen peroxide which exist in thermodynamic equilibrium with the pigment [25].

$$
\begin{gathered}
\text { Mel }+\mathrm{O}_{2} \leftrightarrows \text { Mel semiquinones }+\mathrm{O}_{2}^{\cdot-} \\
\mathrm{QH}_{2}+\mathrm{O}_{2} \leftrightarrows \mathrm{Q}^{\cdot-}+\mathrm{O}_{2}^{\bullet^{-}}+2 \mathrm{H}^{+}
\end{gathered}
$$

where $\mathrm{QH}_{2}$ represents melanin ortho-hydroquinone groups.

However, it is anticipated that at acid $\mathrm{pH}$ the actual concentration of superoxide will be markedly decreased because of its protonation $\left(\mathrm{pK}_{\mathrm{a}}=4.7\right.$, [26]) and subsequent rapid dismutation to $\mathrm{H}_{2} \mathrm{O}_{2}$, and also because of a diminished capability of DM to reduce $\mathrm{O}_{2}$. To find out whether $\mathrm{H}_{2} \mathrm{O}_{2}$ is involved in the nitrite-dependent generation of melanin radicals, CAT $(100 \mu \mathrm{g} / \mathrm{mL})$ was added to DM solution in water $(250 \mu \mathrm{L})$ and the sample was incubated for $5 \mathrm{~min}$. Subsequently $250 \mu \mathrm{L}$ of $\mathrm{pH} 3.6$ acetate buffer $(0.1 \mathrm{M})$ was added followed by the addition of nitrite. Although in the presence of CAT the reference signal (nitrite omitted) was about 20\% less than without CAT, the ratio of the amplitudes from samples containing (DM + nitrite)/(DM) was almost the same as that for (DM + CAT + nitrite)/ $(\mathrm{DM}+\mathrm{CAT})$ suggesting that at this $\mathrm{pH}$ any residual $\mathrm{H}_{2} \mathrm{O}_{2}$ had no apparent effect on the generation of radicals in DM by nitrite. Similar result was obtained when CAT was substituted for SOD which implies that the generation of radicals in DM by nitrite is 
independent on the presence of superoxide/hydroperoxyl in the system.

Because CAT and $\mathrm{H}_{2} \mathrm{O}_{2}$ alone did not affect the melanin signal, this result suggests that $\mathrm{H}_{2} \mathrm{O}_{2}$ (at acid $\mathrm{pH}$ ) may be involved in the nitrite-mediated oxidation of DM, probably through in situ produced peroxynitrite $\left(\mathrm{ONOOH} / \mathrm{ONOO}^{-}\right)$, and perhaps $\mathrm{O}_{2}^{-}$ (at near neutral $\mathrm{pH}$ ).

\section{Effect of ${ }^{\circ} \mathrm{NO}$ and $\mathrm{ONOO}^{-}$}

To gain further insight into the possible mechanisms of oxidation of DM by $\mathrm{HNO}_{2}$ the effects of nitric oxide $\left({ }^{\circ} \mathrm{NO}\right)$ and peroxynitrite $\left(\mathrm{ONOO}^{-}\right)$on the melanin EPR signal were examined. $\mathrm{HNO}_{2}$ exists in an equilibrium with its precursors, nitrogen oxides $\cdot \mathrm{NO}$ and ${ }^{\cdot} \mathrm{NO}_{2}$ (Eqs. (2) and (3)), and both react with a number of biological electron donors causing their oxidation. Therefore, their involvement should also be considered.

$$
\begin{gathered}
2 \mathrm{HNO}_{2} \leftrightarrows \mathrm{N}_{2} \mathrm{O}_{3}+\mathrm{H}_{2} \mathrm{O} \\
\mathrm{N}_{2} \mathrm{O}_{3} \leftrightarrows \cdot \mathrm{NO}+{ }^{\cdot} \mathrm{NO}_{2}
\end{gathered}
$$

In addition, it is known that $\mathrm{NO}$ reacts very rapidly with superoxide forming the strong oxidant peroxynitrite $\left(k_{4}=6.7 \times 10^{9} \mathrm{M}^{-1} \cdot \mathrm{s}^{-1}\right)$ [27].

$$
\cdot \mathrm{NO}+\mathrm{O}_{2}^{\cdot-} \leftrightarrows \mathrm{ONOO}^{-}
$$

The possible involvement of $\mathrm{NO}$ in the generation of melanin radicals was studied using a NO donor $\mathrm{DEA} / \mathrm{NO}$ at $\mathrm{pH} 3.6$ and 7.0. When a $\mathrm{NO}$ donor, DEA/NO, was added to DM in aerated $\mathrm{pH} 7.0$ buffer, the EPR signal amplitude increased fourfold (Fig. 6). In contrast, when a nitrogen-saturated solution of DEA/NO was added to a $\mathrm{N}_{2}$ gassed bubbled DM sample, the increase was, approximately, twofold (Fig. 6). When a deaerated DM sample was preincubated with SOD and CAT (pH 7), and then DEA/NO was added anaerobically, the increase was about $55 \%$ (Fig. 6 ), suggesting that ${ }^{\circ} \mathrm{NO}$ per se does not produce radicals in DM. The small increase was presumably due to residual oxygen in the DM solution. DEA/NO preincubated at $\mathrm{pH} 7$ for $30 \mathrm{~min}$ at room temperature and then added to DM induced no changes in the melanin EPR signal, in agreement with the short half lifetime ( $15 \mathrm{~min})$ of this ${ }^{\circ} \mathrm{NO}$ donor [28]. SOD and CAT (combined) only partially inhibited (ca. 40\%) the generation of new radicals in DM (Fig. 6). (The relationship between these experiments and those carried out using $\mathrm{HNO}_{2}$ is that ${ }^{\circ} \mathrm{NO}$ and $\mathrm{ONOOH} / \mathrm{ONOO}^{-}$can be present in our systems (vide infra)).

When $\mathrm{ONOO}^{-}(2 \mathrm{mM})$ was added to $\mathrm{DM}$ at $\mathrm{pH}$ 3.6 and 7.0 , the melanin signal increased by a factor of 4 (Fig. 6), suggesting the peroxynitrite and peroxynitrous acid might participate in melanin oxidation. The result at $\mathrm{pH} 3.6$ might be questionable because it is known that peroxynitrite solutions are always contaminated with nitrite [22] and, therefore, the observed increase might be attributed to nitrous acid (vide supra, Fig. 2), and not to the action of peroxynitrite itself. However, the result obtained at $\mathrm{pH} 7$, where nitrite alone is inactive, clearly points out to peroxynitrites a likely oxidant of DM.

\section{Discussion}

We have shown that in acidic solutions, especially at $\mathrm{pH}<5.5, \mathrm{NaNO}_{2}$ reacts with DOPA-melanin to produce large quantities of melanin radicals (Figs. 2 and 3). This result suggests that nitrous acid, $\mathrm{HNO}_{2}\left(\mathrm{pK}_{\mathrm{a}}=3.35,[21]\right)$ is involved in the radical generation process. This suggestion is further supported by the observation that at constant $\mathrm{NaNO}_{2}$ the increase in the melanin EPR signal is larger at more acidic $\mathrm{pH}$, and that in the 5.5-3.6 $\mathrm{pH}$ range, the EPR amplitude is linearly dependent on $\mathrm{pH}$ (Fig. 3B). It is also consistent with the results that show that at a given acidic $\mathrm{pH}$, higher concentration of nitrite induced larger increase in the melanin EPR signal. It is seen, that in the condition of experiment (Fig. 4) the high concentrations of $\mathrm{NaNO}_{2}$ had no effect on the DM EPR signal (saturation), suggesting melanin quinones are inaccessible for oxidation by $\mathrm{HNO}_{2}$ due to localization inside the polymer matrix. Additionally, it appears that oxygen plays minimal role in melanin radical formation, because it was found that the concentration of nitrite-induced radicals is only slightly higher in aerated samples compared to air-free samples (Fig. 4, inset). The mechanism of reaction is consistent with the model of radical formation in which the concentration of radical-generation sites in melanin is proportional to its concentration (Fig. 5).

We propose that the interaction of DM with $\mathrm{HNO}_{2}$ involves the oxidation of ortho-hydroquinone groups in the pigment, as described by Eqs. (5)-(7).

$$
\begin{gathered}
\mathrm{QH}_{2}+\mathrm{HNO}_{2} \rightarrow \mathrm{QH}^{\cdot}+{ }^{\cdot} \mathrm{NO}\left(+\mathrm{H}_{2} \mathrm{O}\right) \\
\mathrm{QH}^{\cdot}+\mathrm{HNO}_{2} \rightarrow \mathrm{Q}+{ }^{\cdot} \mathrm{NO}\left(+\mathrm{H}_{2} \mathrm{O}\right)
\end{gathered}
$$

the overall reaction being

$$
\mathrm{QH}_{2}+2 \mathrm{HNO}_{2} \rightarrow \mathrm{Q}+2 \cdot \mathrm{NO}\left(+2 \mathrm{H}_{2} \mathrm{O}\right)
$$

The formation of new melanin radicals can be explained by reaction (5) and by comproportionation of hydroquinone and quinone groups in DM (Eq. (8)), which produces a new equilibrium characterized by the higher content of semiquinone radicals.

$$
\mathrm{QH}_{2}+\mathrm{Q} \leftrightarrows 2 \mathrm{Q}^{\cdot-}+2 \mathrm{H}^{+}
$$

The proposed mechanism is supported by our observation that the exposure of a melanin precursor, such as DOPA, or related catechol(amine)s, to $\mathrm{HNO}_{2}$ produces the respective semiquinone radicals (not shown). This mechanism is consistent with the published literature data on the oxidation of paraand ortho-hydroquinones by $\mathrm{HNO}_{2}$ [29].

In addition to the oxidation of melanin hydroquinones directly by $\mathrm{HNO}_{2}$, species derived from 
$\mathrm{HNO}_{2}$ decomposition might also be involved. In moderately acidic solutions $\mathrm{HNO}_{2}$ exists in equilibrium with ${ }^{\circ} \mathrm{NO}$ and ${ }^{\circ} \mathrm{NO}_{2}$ radicals (Eqs. (2), (3)) and we considered the possibility that they also could react with DM.

Nitric oxide, an intermediate in $\mathrm{HNO}_{2}$-dependent oxidation (Eqs. (5)-(7)), appears to be without any effect on the generation of melanin radicals. Results of our experiments, in which DEA/NO was used as -NO donor, revealed that ${ }^{\circ} \mathrm{NO}$ does not react chemically or physically with DM, unless air was present (double integrals of melanin EPR signals recorded in the absence and presence of the NO donor, DEA/NO $(1 \mathrm{mM})$ were identical within experimental error). The requirement that oxygen be present in order to produce melanin radicals by DEA/NO can be explained assuming that the process is mediated by the in situ formed ${ }^{-} \mathrm{NO}_{2}$ or/and $\mathrm{ONOO}^{-}$species. While $\cdot \mathrm{NO}_{2}$ does indeed react with melanin and efficiently oxidizes melanin generating new melanin radicals [30] (in aerated buffer $(\mathrm{pH}=7.0)$ the generation of radicals in DM by DEA/NO is a very fast process), its role in the present system is rather inefficient because the rate of the $\mathrm{NO}_{2}$ formation from ${ }^{\circ} \mathrm{NO}$ and $\mathrm{O}_{2}$ is slow, being second order in ${ }^{\circ} \mathrm{NO}$ and first order in $\mathrm{O}_{2}[31,32]$. In agreement with this we have found that the concentration of $\mathrm{O}_{2}$ did not change appreciably during the reaction (not shown).

However, participation of the ${ }^{\circ} \mathrm{NO}_{2}$ radical in melanin oxidation could not be verified under applied conditions. This aspect of melanin chemistry is under investigation.

The possibility of the involvement of peroxynitrite stems from the known fact that in aerated solutions DM reduces $\mathrm{O}_{2}$ to $\mathrm{O}_{2}^{--}$(Eq. (1), (1A)), and that the $\mathrm{O}_{2}^{--}$radicals react very fast with ${ }^{\circ} \mathrm{NO}$ to produce $\mathrm{ONOO}^{-}$(Eq. (4), [27]).

At acid $\mathrm{pH}$ the peroxynitrous acid $\left(\mathrm{pK}_{\mathrm{a}} 6.8\right.$ [32]) could be formed from $\mathrm{HNO}_{2}$ and $\mathrm{H}_{2} \mathrm{O}_{2}$ (Eqs. (10) and (11)).

$$
\begin{gathered}
\mathrm{O}_{2}^{--}+{ }^{\cdot} \mathrm{O}_{2} \mathrm{H}+\mathrm{H}^{+} \rightarrow \mathrm{H}_{2} \mathrm{O}_{2}+\mathrm{O}_{2} \\
\mathrm{HNO}_{2}+\mathrm{H}_{2} \mathrm{O}_{2} \rightarrow \mathrm{ONOOH}^{\leftrightarrows}+\mathrm{H}_{2} \mathrm{O} \\
\stackrel{\mathrm{ONOO}^{-}}{ }+2 \mathrm{H}^{+}
\end{gathered}
$$

Peroxynitrite is a powerful oxidizing species, resembling in many respect ${ }^{\circ} \mathrm{OH}$ radical [33]. The involvement of this species in DM oxidation by nitrite at low $\mathrm{pH}$ is suggested by the observation that CAT partially prevented the generation of melanin radicals (Fig. 6). In aerated solutions melanin slowly reduces $\mathrm{O}_{2}$ to $\mathrm{O}_{2}^{--}$, which subsequently dismutates to $\mathrm{H}_{2} \mathrm{O}_{2}$. This dismutation is accelerated in acidic $\mathrm{pH}$, and as a result $\mathrm{H}_{2} \mathrm{O}_{2}$ and melanin coexist, even if the pigment consumes some $\mathrm{H}_{2} \mathrm{O}_{2}$ molecules [34]. Nitrous acid reacts with $\mathrm{H}_{2} \mathrm{O}_{2}$ to form peroxynitrous acid, ONOOH (Eq. (10)).

Although at the present time no exact mechanism(s) of the oxidation of $\mathrm{DM}$ by $\mathrm{HNO}_{2}$ can be given, certain reaction pathways, based on the results of our experiments and the existing literature data, can be proposed. The proposed reaction mechanism (Eq. (7)) is consistent with the mechanism of oxidation by $\mathrm{HNO}_{2}$ of para-hydrobenzoquinone [22] and catechols [35].

\section{Conclusions}

In conclusion, we have shown that the interaction of melanin with nitrite at acidic $\mathrm{pH}(\mathrm{pH}<5.5)$ leads to melanin oxidation and is accompanied by the formation of large number of melanin radicals. The strong dependence of the radical formation on $\mathrm{pH}$ suggests that nitrous acid, $\mathrm{HNO}_{2}$, and/or $\mathrm{HNO}_{2}$ -derived species are involved. The reaction occurs at the expense of melanin hydroquinone groups, which are converted into semiquinone radicals. As a result of this oxidation the concentration of the radicals in melanin could be markedly - more than fourfold - increased. This large increase in the radical content indicates that melanin contains a very high concentration of centers responsible for the deactivation of $\mathrm{HNO}_{2}$.

Because melanin and the RNS may be present simultaneously in melanocytes, cells possessing the capacity of melanin synthesis, our studies suggest that the pigment could function as a natural scavenger of $\mathrm{HNO}_{2}$ and related species in vivo. This property may be pertinent to the biological function of melanin. This suggestion is supported by the report that melanized Cryptococcus neoformans cells exposed to $\mathrm{NaNO}_{2}$ in acidic media show significantly higher survival than nonmelanized cells [36].

Acknowledgments. Partially this work was done in Laboratory of Molecular Biophysics and Chemistry and Pharmacology (National Institute of Environmental Health Sciences, North Carolina). I would like to thank my chief and collaborator Dr Krzysztof Reszka and Dr Collin Chignell for hospitality and friendship.

\section{References}

1. Reszka, K., \& Jimbow, K. (1993). Electron donor and acceptor properties of melanin pigments in the skin. In J. Fuchs \& L. Packer (Eds.), Oxidative stress in dermatology (pp. 287-320). New York: Marcel Dekker, Inc.

2. Sealy, R. C. (1984). Free radicals in melanin formation, structure and reactions. In D. Armstrong, R. S. Sohal, R. G. C. Cutler \& T. R. Slater (Eds.), Free radicals in molecular biology, aging and disease (pp. 67-76). New York: Raven Press.

3. Prota, G. (1992). The role of peroxidase in melanogenesis revisited. Pigment Cell Res., Suppl. 2, 25-31. DOI: 10.1111/j.1600-0749.1990.tb00344.X.

4. Chio, S. S., Hyde, J. S., \& Sealy, R. C. (1982). Paramagnetism in melanins: $\mathrm{pH}$ dependence. Arch. Biochem. Biophys., 215(1), 100-106. DOI: 10.1016/0003-9861(82)90283-1.

5. Lukiewicz, S., Reszka, K., \& Matuszak, Z. (1980). Simultaneous electrochemical-electron spin resonance (SEESR) studies on natural and synthetic melanins. Bioelectrochem. Bioenergetics, 7(1), 153-165. DOI: 10.1016/0302-4598(80)87037-1.

6. Reszka, K. J., \& Chignell, C. F. (1993). EPR and spin-trapping investigation of free radicals from the 
reaction of 4-methoxybenzenediazonium tetrafluoroborate with melanin and melanin precursors. J. Am. Chem. Soc., 115(17), 7752-7760. DOI: 10.1021/ ja00070a021.

7. Felix, C. C., Hyde, J. S., Sarna, T., \& Sealy, R. C. (1978). Interactions of melanin with metal ions. Electron spin resonance evidence for chelate complexes of metal ions with free radicals. J. Am. Chem. Soc., 100(12), 3922-3926. DOI: 10.1021/ja00480a044.

8. Dunford, R., Land, E. J., Rozanowska, M., Sarna, T., \& Truscott, T. G. (1995). Interaction of melanin with carbon- and oxygen-centered radicals from methanol and ethanol. Free Radic. Biol. Med., 19(6), 735-740.

9. Sealy, R. C., Sarna, T., Wanner, E. J., \& Reszka, K. (1984). Photosensitization of melanin: an electron spin resonance study of sensitized radical production and oxygen consumption. Photochem. Photobiol., 40(4), 453-459. DOI: 10.1111/j.1751-1097.1984. tb04617.x.

10. Joshi, M., Strandhoy, J., \& White, W. (1996). Nitric oxide synthase activity is up-regulated in melanoma cell lines: a potential mechanism for metastases formation. Melanoma Res., 6(2), 121-126.

11. Xie, K., Huang, S., Dong, Z., Juang, S. -H., Gutman, M., Xie, Q. -W., Nathan, C., \& Fidler, I. J. (1995). Transfection with the inducible nitric oxide synthase gene suppresses tumorigenicity and abrogates metastasis by K-1735 murine melanoma cells. J. Exp. Med., 181(4), 1333-1343. DOI: 10.1084/jem.181.4.1333.

12. Xie, K., Donng, Z., \& Fidler, I. J. (1996). Activation of nitric oxide synthase gene for inhibition of cancer metastasis. J. Leukoc. Biol., 59(6), 797-803.

13. Dong, Z., Straroselsky, A. H., Qi, X., Xie, K., \& Fidler, I. J. (1994). Inverse correlation between expression of inducible nitric oxide synthase activity and production of metastasis in K-1735 murine melanoma cells. Cancer Res., 54(3), 789-793.

14. Nathan, C. F., \& Hibbs, J. B. Jr (1991). Role of nitric oxide synthesis in macrophage antimicrobial activity. Curr. Opin. Immunol., 3(1), 65-70. DOI: 10.1016/0952-7915(91)90079-G.

15. Jenkins, D. C., Charles, I. G., Thomsen, L. L., Moss, D. W., Holmes, L. S., Baylis, S. A., Rhodes, P., Westmore, K., Emson, P. C., \& Moncada, S. (1995). Roles of nitric oxide in tumor growth. Proc. Natl. Acad. Sci. USA, 92(10), 4392-4396.

16. Salvemini, D., De Nucci, G., Gryglewski, R. J., \& Vane, J. R. (1989). Human neutrophils and mononuclear cells inhibit platelet aggregation by releasing a nitric oxide-like factor. Proc. Natl. Acad. Sci. USA, $86,6328-6332$

17. Tannock, I. F., \& Rotin, D. (1989). Acid pH in tumors and its potential for therapeutic exploitation. Cancer Res., 49(16), 4373-4383.

18. Vitturi, D. A., \& Patel, R. P. (2011). Current perspectives and challenges in understanding the role of nitrite as an integral player in nitric oxide biology and therapy. Free Radic. Biol. Med., 51(4), 805-812. DOI: 10.1016/j.freeradbiomed.2011.05.037.

19. Bhatnagar, V., Anjaiah, S., Puri, N., Darshanam, B. N. A., \& Ramaiah, A. (1993). pH of Melanosomes of B 16 murine melanoma is acidic: Its physiological importance in the regulation of melanin biosynthesis. Arch. Biochem. Biophys., 307(1), 183-192.
20. Seiji, M., \& Kukicha, A. (1969). Acid phosphatase activity in melanosomes. J. Invest. Dermatol., 52(2), 212-216. DOI: 10.1038/jid.1969.33.

21. Ebbing, D. D. (1990). General chemistry, 3rd ed. Boston: Houghton Mifflin Company.

22. Beckman, J. S., Chen, J., Ischiropoulos, H., \& Crow, J. P. (1994). Oxidative chemistry of peroxynitrite. In L. Packer (Ed.), Oxygen radicals in biological systems, Part C (Vol. 233, pp. 229-240). San Diego: Academic Press

23. Hughes, M. N., \& Nicklin, H. G. (1968). The chemistry of pernitrites. Part I. Kinetics of decomposition of pernitrous acid. J. Chem. Soc. A, 1968, 450-452 DOI: $10.1039 / \mathrm{J} 19680000450$.

24. Duling, D. (1994). Simulation of multiple isotropic spin-trap EPR spectra. J. Magn. Reson., Series B, 104(2), 105-110.

25. Korytowski, W., \& Sarna, T. (1990). Bleaching of melanin pigments. Role of copper ions and hydrogen peroxide in autooxidation and photooxidation of synthetic dopa-melanin. J. Biol. Chem., 265(21), 12410-12416.

26. Bielski, B., Cabelli, D. E., Arudi, R. L., \& Ross, A. B. (1985) Reactivity of $\mathrm{HO}_{2} / \mathrm{O}_{2}^{-}$radicals in aqueous solution. J. Phys. Chem. Ref. Data, 14(4), 1041-1096.

27. Huie, R. E., \& Padmaja, S. (1993) The reaction of NO with superoxide. Free Radic. Res. Commun., 18(4), 195-199. DOI: 10.3109/10715769309145868.

28. Davies, K. M., Wink, D. A., Saavedra, J. E., \& Keefer, L. K. (2001). Chemistry of the diazeniumdiolates. 2. Kinetics and mechanism of dissociation to nitric oxide in aqueous solution. J. Am. Chem. Soc., 123(23), 5473-5481. DOI: 10.1021/ja002899q.

29. Beake, B. D., Moodie, R. B., \& Sandall, P. B. (1994). The kinetics and mechanism of oxidation of hydroquinone and chlorohydroquinone in the presence of nitrous acid in aqueous acid solution. J. Chem. Soc., Perkin Trans., 2, 957-960. DOI: 10.1039/ P29940000957.

30. Reszka, K. J., Matuszak, Z., \& Chignell, C. F. (1998). Lactoperoxidase-catalyzed oxidation of melanin by reactive nitrogen species derived from nitrite - An EPR study. Free Radic. Biol. Med., 25(2), 208-216. DOI: 10.1016/S0891-5849(98)00058-6.

31. Ford, P. C., Wink, D. A., \& Stanbury, D. M. (1993). Autoxidation kinetics of aqueous nitric oxide. FEBS Lett., 326(1/3), 1-3. http://dx.doi.org/10.1016/00145793(93)81748-O.

32. Pryor, W. A., \& Squadrito, G. L. (1995). The chemistry of peroxynitrite: a product from the reaction of nitric oxide with superoxide. Am. J. Physiol. (Lung Cell Mol. Physiol.), 268(5), L699-L722.

33. Beckman, J. S., Beckman, T. W., Chen, J., Marshall, P. A., \& Freeman, B. A. (1990). Apparent hydroxyl radical production by peroxynitrite: implications for endothelial injury from nitric oxide and superoxide. PNAS, 87(4), 1620-1624. DOI: 10.1073/pnas.87.4.1620.

34. Korytowski, W., Pilas, B., Sarna, T., \& Kalyanaraman, B. (1987). Photoinduced generation of hydrogen peroxide and hydroxyl radicals in melanins. Photochem. Photobiol., 45(2), 185-190. DOI: 10.1111/j.17511097.1987.tb05362.x.

35. Wang, Y., \& Casadevall, A. (1994). Susceptibility of melanized and nonmelanized Cryptococcus neoformans to nitrogen- and oxygen-derived oxidants. Infect. Immun., 62(7), 3004-3007. 